\title{
Inhibition of microRNA-711 limits angiopoietin-1 and Akt changes, tissue damage, and motor dysfunction after contusive spinal cord injury in mice
}

Boris Sabirzhanov ${ }^{1}$, Jessica Matyas ${ }^{1}$, Marina Coll-Miro ${ }^{1}$, Laina Lijia Yu ${ }^{1}$, Alan I. Faden ${ }^{1,2}$, Bogdan A. Stoica ${ }^{1}$ and Junfang $\mathrm{Wu}^{1,2}$

\begin{abstract}
Spinal cord injury (SCI) causes neuronal cell death and vascular damage, which contribute to neurological dysfunction. Given that many biochemical changes contribute to such secondary injury, treatment approaches have increasingly focused on combined therapies or use of multi-functional drugs. MicroRNAs (miRs) are small (20-23 nucleotide), nonprotein-coding RNAs and can negatively regulate target gene expression at the post-transcriptional level. As individual miRs can potentially modulate expression of multiple relevant proteins after injury, they are attractive candidates as upstream regulators of the secondary SCl progression. In the present study we examined the role of miR-711 modulation after $\mathrm{SCl}$. Levels of miR-711 were increased in injured spinal cord early after SCl, accompanied by rapid downregulation of its target angiopoietin-1 (Ang-1), an endothelial growth factor. Changes of miR-711 were also associated with downregulation of the pro-survival protein Akt (protein kinase B), another target of miR-711, with sequential activation of glycogen synthase kinase 3 and the pro-apoptotic BH3-only molecule PUMA. Central administration of a miR-711 hairpin inhibitor after SCI limited decreases of Ang-1/Akt expression and attenuated apoptotic pathways. Such treatment also reduced neuronal/axonal damage, protected microvasculature and improved motor dysfunction following SCl. In vitro, miR-711 levels were rapidly elevated by neuronal insults, but not by activated microglia and astrocytes. Together, our data suggest that post-traumatic miR-711 elevation contributes to neuronal cell death after $\mathrm{SCl}$, in part by inhibiting Ang-1 and Akt pathways, and may serve as a novel therapeutic target.
\end{abstract}

\section{Introduction}

Traumatic spinal cord injury (SCI) initiates a complex cascade of molecular events that leads to progressive degeneration. These secondary injury processes include induction of multiple neuronal cell death pathways and vascular disruption, leading to neuronal loss, axonal

\footnotetext{
Correspondence: Junfang Wu (junfang.wu@som.umaryland.edu)

'Department of Anesthesiology and Center for Shock, Trauma and

Anesthesiology Research (STAR), School of Medicine, Baltimore, MD, USA

${ }^{2}$ University of Maryland Center to Advance Chronic Pain Research, University of

Maryland Baltimore, Baltimore, MD 21201, USA

These authors contributed equally: Boris Sabirzhanov, Jessica Matyas

Edited by A. Verkhratsky
}

damage, and neurological dysfunction. The failure of effective clinical therapeutic interventions for SCI likely reflects, in part, the incomplete understanding of complex secondary injury mechanisms and the historical emphasis on targeting single injury mechanisms.

MicroRNAs (miRs) are short (20-23 nucleotide) noncoding RNA molecules that negatively regulate gene expression at the post-transcriptional level by binding to the $3^{\prime}$-untranslated region (UTR) of target mRNAs, leading to their degradation and/or translational inhibition $^{1}$. As single miRs can simultaneously modulate the expression of various proteins in multiple pathways, miRs

\section{(c) The Author(s) 2019}

(c) (i) Open Access This article is licensed under a Creative Commons Attribution 4.0 International License, which permits use, sharing, adaptation, distribution and reproduction in any medium or format, as long as you give appropriate credit to the original author(s) and the source, provide a link to the Creative Commons license, and indicate if changes were made. The images or other third party material in this article are included in the article's Creative Commons license, unless indicated otherwise in a credit line to the material. If material is not included in the article's Creative Commons license and your intended use is not permitted by statutory regulation or exceeds the permitted use, you will need to obtain permission directly from the copyright holder. To view a copy of this license, visit http://creativecommons.org/licenses/by/4.0/. 
are potentially attractive upstream regulatory targets for secondary SCI. A number of miRNAs are enriched in neuronal cells and have important roles in central nervous system (CNS) development, function and pathologyincluding synaptic plasticity, dendritogenesis and structural remodeling ${ }^{2}$. Due to their ability to regulate entire networks of genes ${ }^{3}$, neuronal miRs can act as "metacontrollers" of CNS gene expression ${ }^{4,5}$. Recent studies indicate that miRs are involved in the pathophysiology of CNS ischemia and trauma ${ }^{6-14}$. Although miRs have been shown to modulate neuronal cell death pathways, few have been directly evaluated within the context of $\mathrm{SCl}^{11-14}$, and their mechanisms of action in this regard remain largely unknown. It has been suggested that concurrent inhibition of multiple pro-apoptotic molecules, such as members of the BH3-only family of pro-apoptotic genes, may underlie the strong anti-apoptotic effects of certain miRs $^{15-17}$.

We have recently initiated a comprehensive effort to explore changes in miRs expression after mouse $\mathrm{SCI}$, using microarray analyses followed by qPCR validation. Among miRs showing highly significant changes early after traumatic injury in vivo was miR-711. Previous studies have suggested that among the mRNA targets with potential sites for miR-711 in their $3^{\prime}$ UTR are several neuroprotective molecules, including Akt (protein kinase B) and angiopoietin-1 (Ang-1) ${ }^{18-20}$. The intracellular Akt/ glycogen synthase kinase (GSK) $\beta$ signaling pathway appears to be essential for regulating axonal growth; inhibition of this pathway has proven neuroprotective and shows axon-growth-promoting effects in $\mathrm{SCI}^{21-25}$. Ang- 1 is known to protect endothelial cell survival and also to preserve the integrity of endothelial cell tight junctions under pathological conditions ${ }^{26,27}$. We recently demonstrated that Ang-1 is a target for miR-711 in neuronal injury $^{28}$. Ang-1 can limit neuronal apoptosis, an effect that involves Tie-2 (Ang-1 receptor)-mediated activation of the phosphatidylinositol 3-kinase (PI3K)/Akt pathway and inhibition of caspase- 3 cleavage ${ }^{29}$. In addition, Ang- 1 promotes axonal remodeling and neurite outgrowth in vitro and after brain ischemia ${ }^{30-32}$.

The goal of this study was to determine whether SCIinduced elevation of miR-711 contributes to neuronal and axonal damage through inhibition of Akt and Ang-1 signaling, as well as whether miR-711 inhibition can reduce secondary injury after SCI. We first examined the temporal expression profiles of miR-711 and its known targets in a well-established mouse contusion SCI model. MiR711 hairpin inhibitor or negative control-treated mice were compared with assess the role of miR-711 in neuronal cell death, axonal damage and associated neurological dysfunction.

\section{Results}

miR-711 is upregulated in the injured spinal cord tissue

miRNA microarray profiling by GeneChip miRNA array revealed that CNS trauma significantly upregulate the level of miR-711 in the ipsilateral cortex of controlled cortical impact mice ${ }^{33}$ as well as the injured spinal cord (data not shown). Here we performed a detailed expression profiling of miR-711 in the injured spinal cord after a moderate contusion SCI in mice. qPCR analysis demonstrated a rapid and persistent upregulation (9-10-folds) of miR-711 ( $n=5-6$ mice/group), starting as early as $6 \mathrm{~h}$ post-injury, and persisting through 7 days (Fig. 1).

\section{Central administration of miR-711 hairpin inhibitor increases the level of Akt and phosphorylation of its targets in the injured spinal cord}

To assess whether miR-711 elevation is upstream of Akt pathway inhibition and BH3-only activation after SCI we administered miR-711 hairpin inhibitors or negative control after SCI (intrathecal injection, $0.5 \mathrm{nmol}$; right after injury) as previously described ${ }^{34}$. At $24 \mathrm{~h}$ after injection, western blot analysis demonstrated that SCI significantly decreased levels of Akt ( $p<0.001$, vs. Sham), general phosphorylated Akt and specifically phosphorylated Akt $(p<0.01$, vs. Sham, Fig. 2a, b), and markedly downregulated phosphorylation of Akt substrates GSK3 $\alpha$ / $\beta$ (Fig. 2c, $p<0.001$, vs. Sham). Total GSK $3 \alpha / \beta$ levels were unaltered at $24 \mathrm{~h}$ after SCI (Fig. 2d). Notably, miR-711 hairpin inhibitors significantly reversed these changes and upregulated the total and activated (pSer473, pThr308) Akt $(p<0.01$, vs. SCI/Veh), increased Akt-dependent

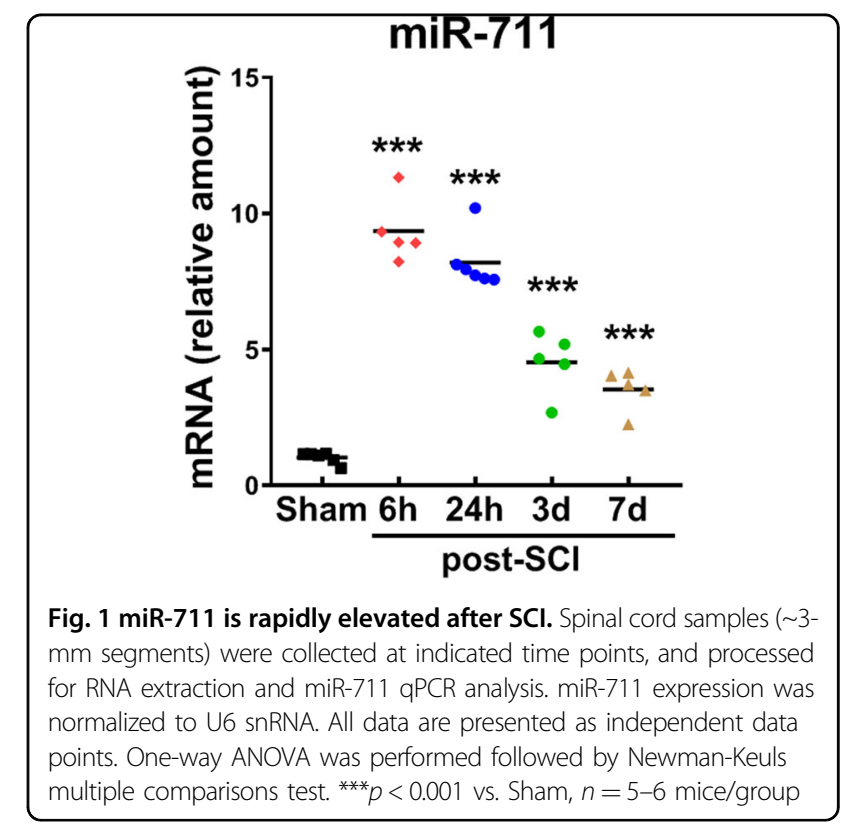




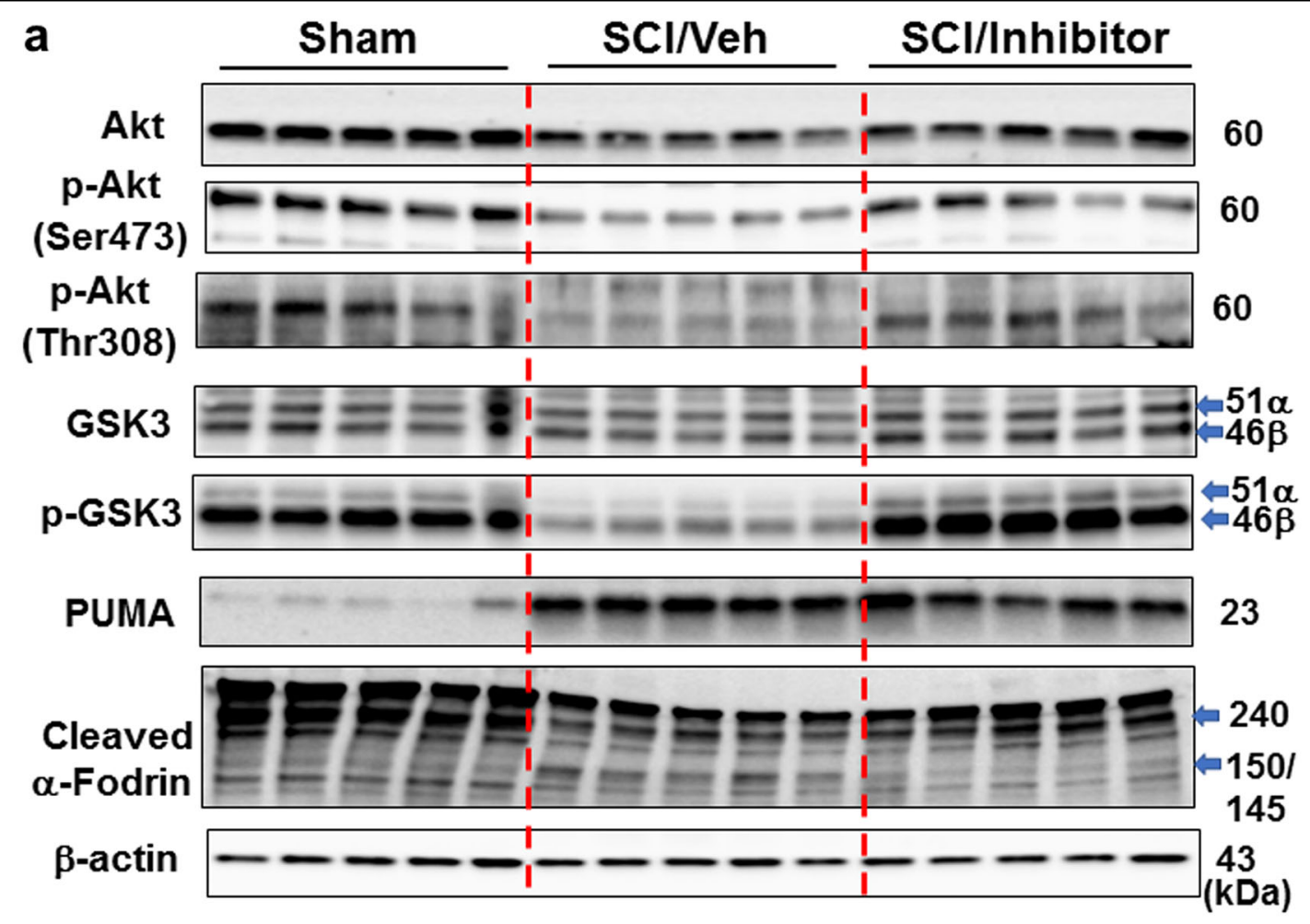

b
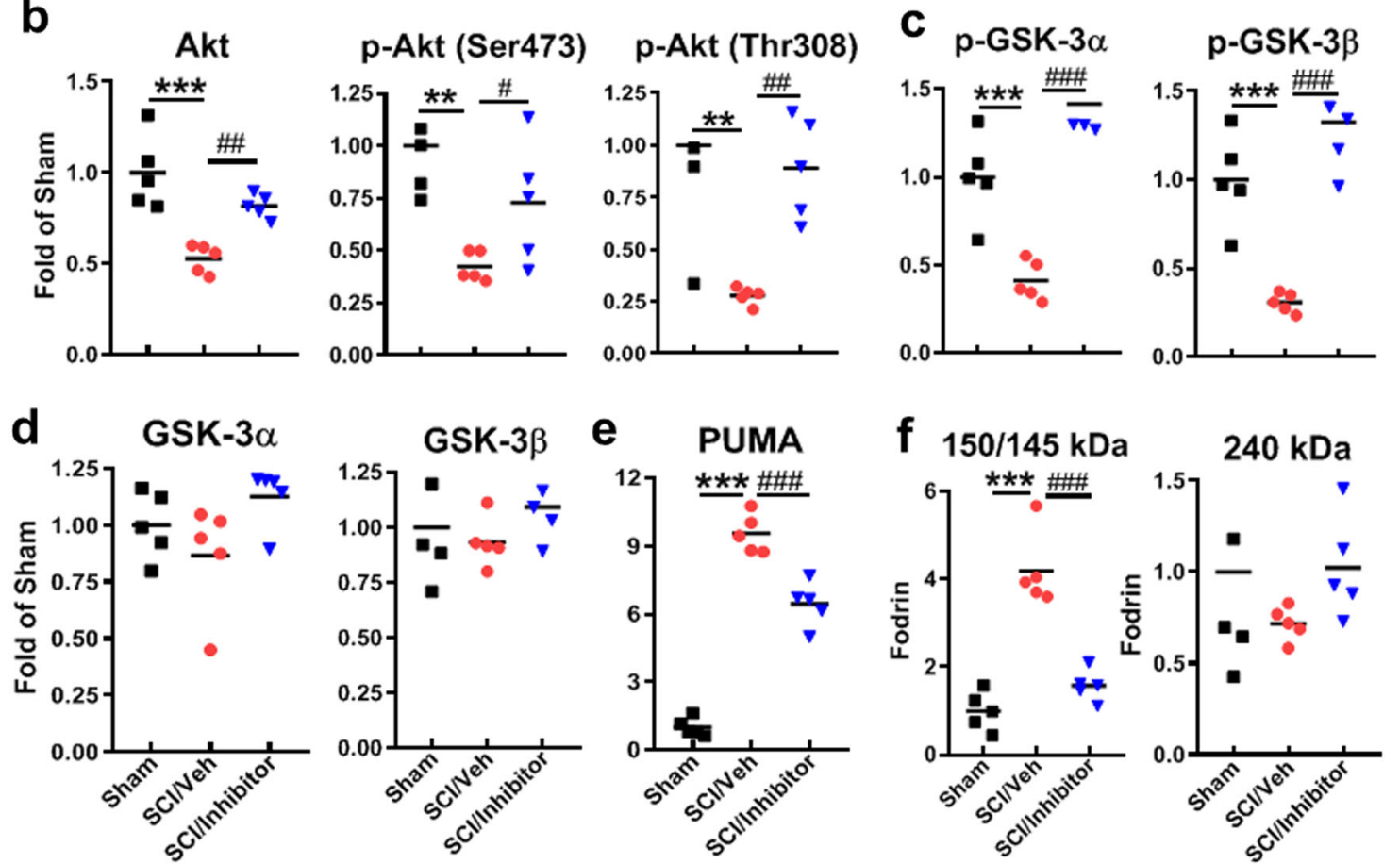

Fig. 2 Intrathecal administration of miR-711 hairpin inhibitor increases Akt/GSK3a/ $\beta$ signaling and attenuates expression of PUMA and apoptotic marker fodrin cleavage at $\mathbf{2 4} \mathbf{h}$ after SCl. Mice were treated with miR-711 hairpin inhibitor or negative control (vehicle) at 5 min postinjury. a Representative western blots for total Akt, phosphorylated Akt (p-Akt, Ser473, Thr308), total and phosphorylated GSK3a/ $\beta$, PUMA, cleaved afodrin. b-f Protein levels were quantified by densitometry, normalized to $\beta$-actin, and presented as fold change compared with sham-injured controls. All data are presented as independent data points. One-way ANOVA was performed followed by Newman-Keuls multiple comparisons test. $n=5 /$ group. ${ }^{* *} p<0.01,{ }^{* * *} p<0.001$ vs. Sham; ${ }^{\#} p<0.05,{ }^{\# \#} p<0.01 ;{ }^{\# \#} p<0.001$ vs. SCI/Vehicle group 
phosphorylation (inhibition) of GSK $3 \alpha / \beta$ ( $n=5$ mice/ group, $p<0.001$, vs. SCI/Veh). We did not observe differences between Sham/inhibitor and Sham/Vehicle groups (data not shown).

Next, we examined the effect of miR-711 inhibition on SCI-mediated upregulation of pro-apoptotic member of Bcl-2 family PUMA (Bcl2-binding component 3 ), which expression at least in part downregulated by Akt pathway. SCI resulted in a 10-fold increase of BH3-only molecules PUMA $(p<0.001$, vs. Sham/Veh). Treatment with the miR-711 hairpin inhibitor significantly decreased injurydependent activation of PUMA after SCI (Fig. 2e, $p<0.001$, vs. SCI/Veh). Furthermore, cleavage of the cell death marker $\alpha$-fodrin, was assessed in the injured spinal cord at $24 \mathrm{~h}$ post-injury. $150 / 145 \mathrm{kDa}$ fragments of $\alpha$ fodrin cleavage were increased 4-5-fold, whereas fulllength protein $(240 \mathrm{kDa})$ and the level of $120 \mathrm{kDa}$ fragment were slightly decreased in SCI versus sham spinal cord. These changes were significantly attenuated in SCI mice treated with miR-711 inhibitor (Fig. 2f, $p<0.001$, vs.
SCI/Veh), confirming reduced cell death upon miR-711 inhibition. We observed no differences of miR-711 inhibitor in sham mice compared with Sham/Vehicle group (data not shown).

miR-711 hairpin inhibitor confers neuroprotection in the injured spinal cord

To determine whether neuronal damage after SCI is dependent on miR-711 activity, we treated SCI mice with miR-711 hairpin inhibitors or negative control right after injury followed by an additional treatment at $24 \mathrm{~h}$ postinjury. Immunohistochemistry (IHC) staining with axonal marker of phosphorylated neurofilament antibody SMI-31 indicated axonal damage or loss in the injured spinal cord at 6-week post-injury (Fig. 3a, b, $p<0.01$, vs. Sham). Importantly, inhibition of miR-711 significantly increased intensity of SMI- $31+$ signals $(p<0.05$, vs. SCI/Veh). Thus, elevated miR-711 appears to contribute to axonal damage in injured spinal cord. Furthermore, NeuN + neurons were also determined at 6 weeks after SCI (Fig. 3c). SCI
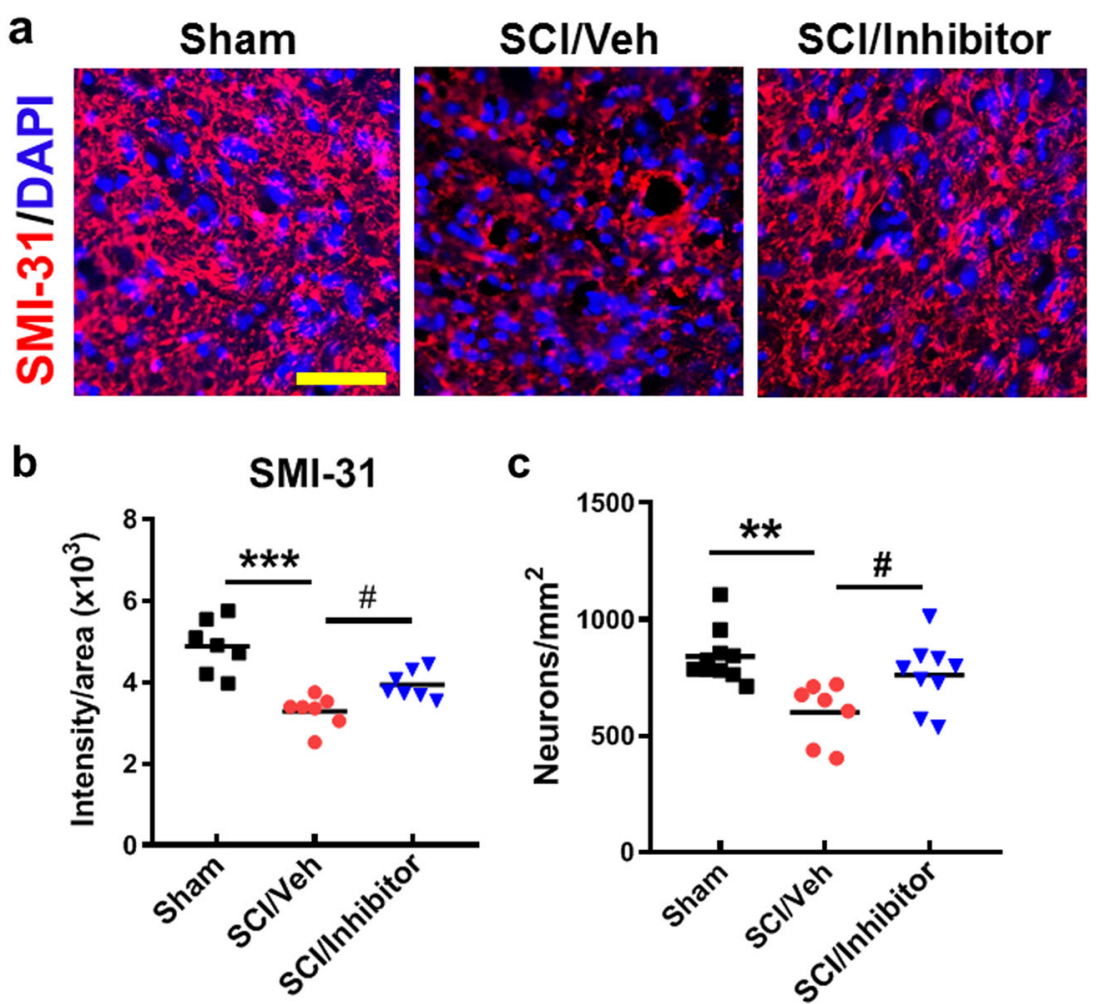

Fig. 3 Central administration of miR-711 hairpin inhibitor improves axonal and neuronal survival at 6 weeks after SCl. SCl mice were treated with miR-711 hairpin inhibitors or negative control (vehicle) right after injury followed by an additional treatment at $24 \mathrm{~h}$ post-injury. Immunohistochemistry (IHC) staining with axonal marker of phosphorylated neurofilament antibody SMI-31 as well as neuronal marker (NeuN) was performed in the spinal cord coronal sections at 6-week post-injury. a Images $(\times 20)$ of spinal cord sections of Sham, SCI/Neh, and SCl/Inhibitor mice stained with antibodies against SMI-31 (red) and DAPI (blue). Scale bars $=50 \mu \mathrm{m}$. b Quantification of SMI-31 immunointensity. c Quantification of NeuN/DAPI positive cells. The data are presented as independent data points. One-way ANOVA was performed followed by Newman-Keuls multiple comparisons test. $N=7$ /group. ${ }^{* *} p<0.01,{ }^{* *} p<0.01$ vs. Sham; ${ }^{*} p<0.05$ vs. SCINeh 
resulted in $30 \%$ of neuronal cell loss, whereas miR-711 inhibitors significantly improved neuronal survival when compared with vehicle-treated samples.

Ang-1 is rapidly downregulated in the injured spinal cord and reversed by miR-711 hairpin inhibitor

To examine effects of SCI on Ang-1 expression, qPCR and western blot analysis were performed in injured spinal cord tissues. There was rapid reduction of Ang-1 mRNA level at $6 \mathrm{~h}$ post-injury, with the lowest level at $24 \mathrm{~h}$, and remained low level up to 3 days (Fig. $4 \mathrm{a}, n=5$ mice/group). This was confirmed by western blot at day 1 post-injury (Fig. 4b, $n=4$ mice/group, $p<0.001$, vs. Sham). Importantly, intrathecal administration of the miR-711 hairpin inhibitor significantly increased expression of Ang-1 compared with vehicle treatment (Fig. 4c, $p<0.05$, vs. SCI/Veh), supporting the notion that Ang- 1 is a downstream target of miR-711.

Treatment with miR-711 inhibitor results in significant SClinduced disinhibition of vascular density

To determine effects of miR-711 on the blood vessels, we performed IHC with endothelial marker von Willebrand factor (vWF) that is expressed specifically in the cytoplasm of endothelial cells and that have been used to identify vascular structure after CNS injury ${ }^{35,36}$. We observed that vWF immunointensity was significantly reduced at the injury site 6 weeks post-injury (Fig. 5a), indicating disrupted vascular density. SCI mice treated with miR-711 hairpin inhibitors right after injury followed by an additional treatment at $24 \mathrm{~h}$ post-injury showed significant increase of vWF immunointensity when compared with SCI/Veh group (Fig. 5b). This suggests the possibility that elevated miR-711 leads to downregulation of Ang-1, resulting in blood vessels damage and leaky, subsequent detrimental inflammation after SCI.

\section{Inhibition of miR-711 improves motor function and reduces tissue damage}

To assess effects of miR-711 on locomotor functional recovery after SCI, miR-711 hairpin inhibitor-treated and negative control miR-treated SCI mice were tested in the open field on days 1, 3, and weekly up to 6 weeks postinjury. At day 1 after SCI, all mice had a BMS locomotor score of 0 or 1 , indicating nearly complete loss of motor function (Fig. 6a). By 1 week after injury, miR-711 inhibitor-treated mice $(n=13)$ had significantly improved BMS scores compared with SCI/Veh animals $(n=11$, Fig. $6 \mathrm{a}, p<0.05)$ which remained through 6 weeks after injury [Post-injury Days: $\mathrm{F}(7,176)=41.021, p<0.001$; Drug: $\mathrm{F}(1$, $176)=35.186, p<0.001$; the interaction of Post-injury Days $\times$ Drug: $\mathrm{F}(7,176)=1.493 ; p=0.173$; repeated measures two-way ANOVA with Newman-Keuls multiple comparisons test].
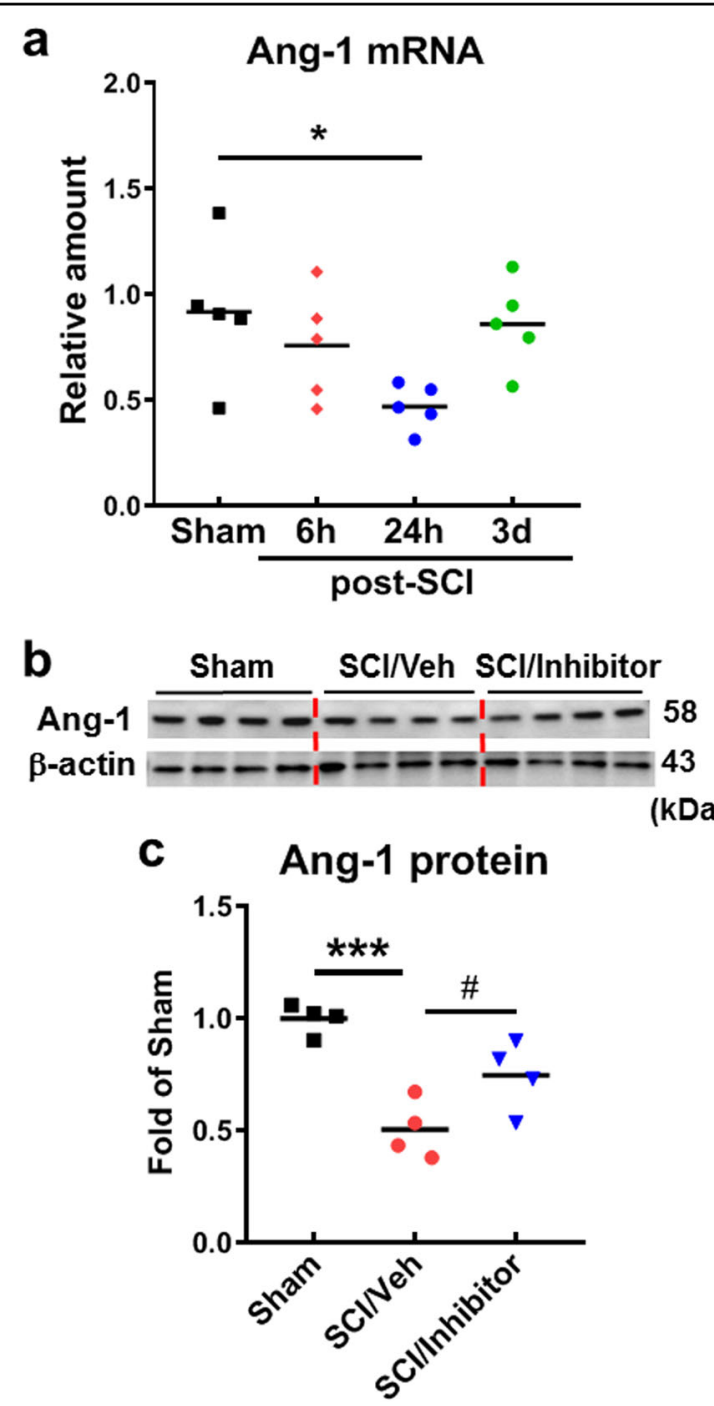

(kDa)

Fig. 4 SCl-induced downregulation of Ang-1 expression is significantly attenuated by intrathecal injection of miR-711 inhibitor at day 1 post-injury. a Quantification of Ang- 1 mRNA by qPCR analysis at indicated time points after injury. $n=5-6$ mice/ group. $\mathbf{b}$ Expression of Ang-1 protein in the spinal cord tissue surrounding injury site following $\mathrm{SCl}$ in mice. $\beta$-actin was used as a loading control. c Quantification of Ang-1 data from (b). $n=4$ mice/ group. The data are presented as independent data points. One-way ANOVA was performed followed by Newman-Keuls multiple comparisons test. ${ }^{*} p<0.05,{ }^{* *} p<0.001$, vs. Sham; ${ }^{*} p<0.05$ vs. SCI/ Veh

Next, more refined quantitative gait analysis by CatWalk was used to detect differences in general motor coordination. At 5 weeks of SCI, the mice that regained adequate locomotor function to be able to withdraw a hindpaw or with plantar position were assessed for CatWalk gait analysis. Print Position is the distance between the position of the hindpaw and the position of the previously placed front paw on the same side of the body and in the same step cycle. A health mouse results in a print 


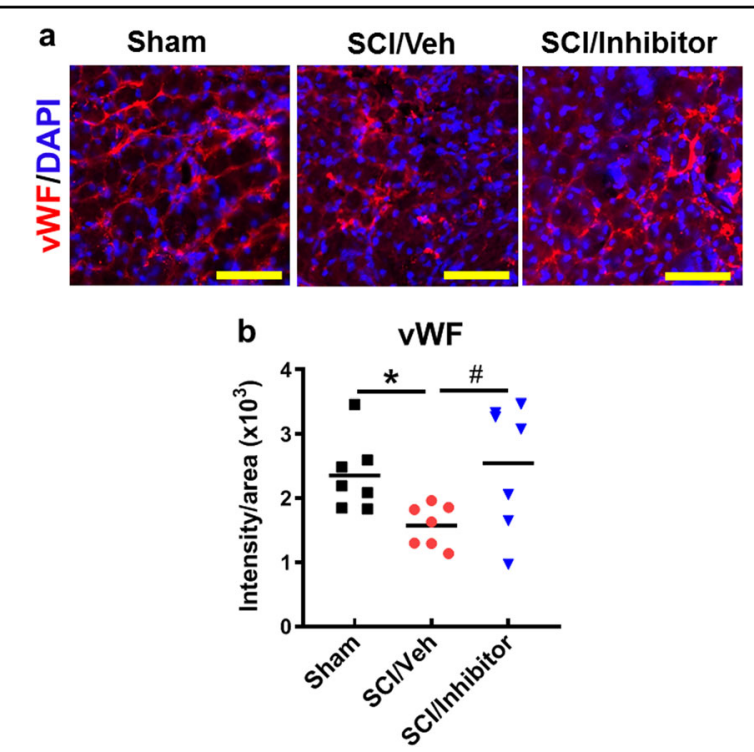

Fig. 5 Central administration of miR-711 hairpin inhibitor results in significant $\mathrm{SCl}$-induced disinhibition of vascular density labeled with endothelial marker von Willebrand factor (vWF, red). a Representative images from sham or injured spinal cord at 6 weeks post-injury. Scale bars $=50 \mu \mathrm{m}$. b Quantification of vWF intensity area. The data are presented as independent data points. One-way ANOVA was performed followed by Newman-Keuls multiple comparisons test. $n=7 /$ group. ${ }^{*} p<0.01$ vs. Sham; ${ }^{\#} p<0.05$ vs. SCl/ Veh

position score typically approaching $0-1 \mathrm{~cm} . \mathrm{SCI}(n=7)$ resulted in significant increase in print positions compared with Sham animals $(n=10$, Fig. $6 b, p<0.001)$. Remarkably, miR-711 inhibitor-treated mice $(n=8)$ showed significant improvement in print placement compared with SCI/Veh animals (Fig. 6b, $p<0.01$ ). To evaluate overall motor coordination, regularity index, a parameter under the category of step sequencing, was selected. Step sequence regularity index expresses the number of normal step sequence patterns relative to the total number of paw placements. It is a fractional measure of inter-paw coordination. In healthy, fully coordinated animals its value is $100 \%{ }^{37}$, though in practice, naive mice typically approach $80-90 \%$ (Fig. 6c). In response to SCI, the regularity index in SCI/Veh $(n=7)$, which was robustly reduced compared with Sham animals $(n=10$, Fig. $6 \mathrm{~d}, p<$ 0.001 ), strikingly appeared to be significantly restored in miR-711 inhibitor-treated mice $(n=8, \quad p<0.01)$, approaching $50 \%$ normal stepping. Together, inhibition of miR-711 significantly improves recovery of locomotor function and motor coordination following SCI.

To determine if the observed behavioral improvement may relate to increased residual white mater, spinal cord sections from injured mice perfused at 6 weeks were stained with LFB for myelinated WM area at $200 \mu \mathrm{m}$ intervals rostral (R) and caudal (C) to the injury epicenter
(EPI). Histological analysis revealed that there was a significant increase of the area of white matter sparing in the miR-711 inhibitor-treated mice compared with SCI/Veh group (Fig. 7). Representative LFB stained sections at the epicenter of each subject illustrate the differences in myelinated WM area between miR-711 inhibitor and the vehicle-treated animals (Fig. 7a). These data indicate that inhibition of miR-711 improves the recovery of motor function and reduces the degree of hyperesthesia after $\mathrm{SCI}$, which is associated with increased WM.

\section{miR-711 is highly expressed by neurons in vitro}

miR-711 level has been shown to be rapidly elevated by neuronal insults in vitro ${ }^{33}$. To compare miR-711 expression levels in CNS different cell types, primary neurons, microglia, and astrocytes were cultured from rat embryonic or neonatal cortices. Primary cortical neurons were incubated with cell death inducers etoposide (Etop) or staurosporine (Stau) for $6 \mathrm{~h}$. In consistent with our previous report ${ }^{33}$, Etop or Stau-induced neuron apoptosis resulted in significant elevation in levels of miR-711 compared with control neurons $(n=3-5$ dishes, Fig. 8a, $p<0.001)$. Primary microglia were exposed to lipopolysaccharide (LPS) or interferon $\gamma$ (IFN $\gamma$ ) for $24 \mathrm{~h}$, separately. To activate astrocytes, LPS, transforming growth factor $\beta 1$ (TGF $\beta 1$ ), or $10 \%$ fetal bovine serum (FBS) were applied to the cultures, separately. After $24 \mathrm{~h}$ treatment, the cells were harvested for RNA extraction and miR-711 analysis. We found extremely lower basal level of miR-711 in primary cultured astrocytes and microglia than that in cultured cortical neurons $(p<0.001)$. Moreover, activated microglia and astrocytes failed to stimulate miR-711 expression (Fig. 8a). These data suggest that miR-711 is predominately expressed by neurons.

\section{Discussion}

In order to identify "master regulators" of post-traumatic apoptosis, we initially focused on miR changes in the first hours to days after SCI, a period associated with maximal secondary neuronal cell death. Among miRs showing highly significant changes early after traumatic injury in vivo was miR-711, which was markedly (9-10-fold) and rapidly ( $6 \mathrm{~h}$ post-injury) upregulated. We also focused on miR-711 because it was predicted to target several key regulatory factors including Akt and Ang-1. In addition, miR-711 expression is robustly upregulated for days in injured brain after TBI as well as in the heart after ische$\mathrm{mia} /$ reperfusion insult ${ }^{20,33}$. Our results show that SCI induces elevation of miR-711 expression and reduction of its targets Akt and Ang- 1 as early as $6 \mathrm{~h}$ post-injury. Blocking miR-711 activation by using miRIDIAN Hairpin Inhibitors limits SCI-mediated Akt/GSK3 $\beta$ and Ang-1 inactivation, leading to neuroprotective effects. Importantly, acute miR-711 inhibition significantly reserved 


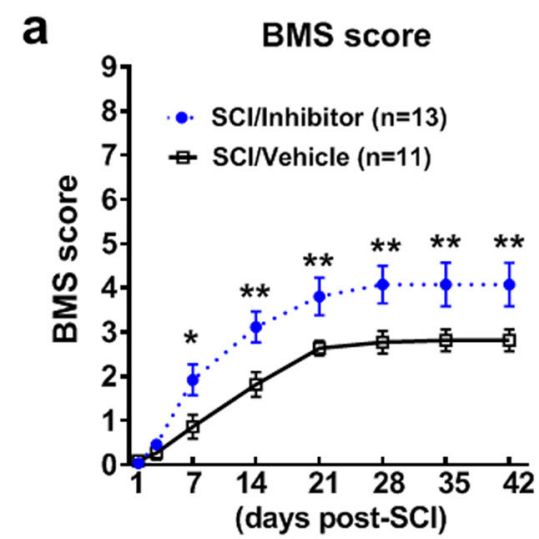

\section{Cham}

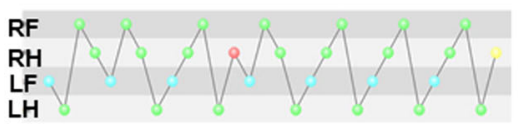

$\mathrm{SCl} / \mathrm{Veh}$

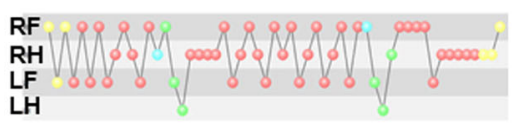

\section{SCI/Inhibitor}

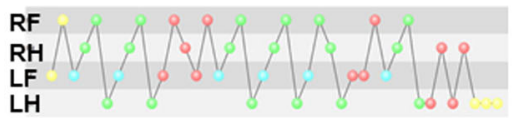

b Print position (cm)

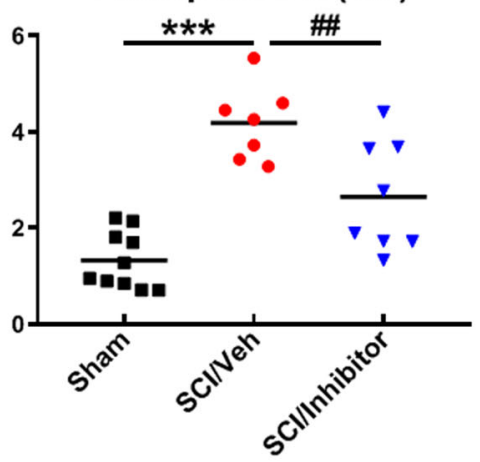

d

Regularity Index (\%)

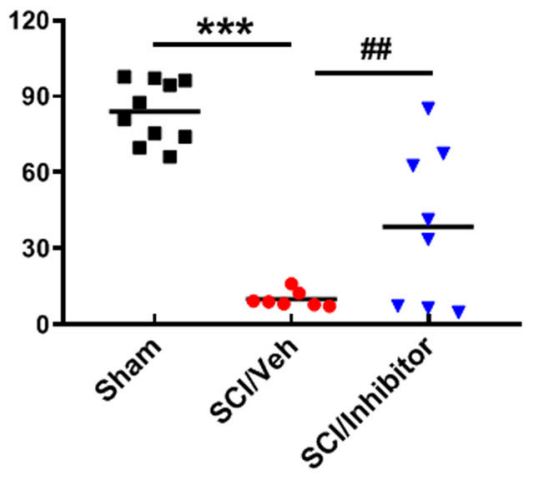

Fig. 6 Inhibition of miR-711 improves motor function after SCI. a Hindlimbs locomotor function after SCI were evaluated using the Basso Mouse Scale (BMS). The data are presented as mean \pm standard error of the mean. Two-way ANOVA with repeated measurements were used followed by Newman-Keuls multiple comparisons test. $n=11$ (SCI/Veh) and 13 (SCl/Inhibitor). ${ }^{*} p<0.05,{ }^{* *} p<0.01$ vs. SCI/Nehicle. b-d Motor coordination was evaluated by CatWalk at 5 weeks post-injury. miR-711 hairpin inhibitor treatment attenuated SCl-induced deficits in print position (b). Representative step sequences (inter-paw coordination) are indicated in (c), where Yellow-not taken into account; Blue-start of a pattern; Green-part of a pattern; Red-not part of a pattern. LH, LR, RH, \& RF: left or right hindpaw \& forepaw. miR-711 inhibitor-treated mice demonstrated more regular gait patterns than vehicle group (d). The data are presented as independent data points. One-way ANOVA was performed followed by Newman-Keuls multiple comparisons test. $n=10$ (Sham), 7 (SCINeh), and 8 (SCI/Inhibitor). ${ }^{* *} p<0.001$ vs. Sham $/$ veh; ${ }^{\# \#} p<0.01$ vs. SCINeh

spared white matter and improved behavioral recovery after SCI.

Neurotrauma-mediated dysregulated Akt expression has been controversial. Some studies reported rapidly decreased Akt levels ${ }^{33,38-41}$, whereas others showed increased levels of total and phosphorylated $\mathrm{Akt}^{42,43}$. We found that Akt is robustly downregulated in the injured spinal cord after moderate contusive SCI. This reduction, including both the phosphorylated form and total Akt, suggests a pathophysiological role for Akt dysregulation, consistent with our previous report in a mouse TBI model $^{17,33}$. These divergent reports may reflect different lesion paradigms and tissue sampling or time windows after injury. Nonetheless, endogenous activation of Akt in neurons may represent a neuroprotective response to injury. Ambacher et al. ${ }^{44}$ reported that Akt-dependent phosphorylation on Ser9 is a key mechanism that inactivates GSK3 $\beta$. It is known that GSK3 $\beta$ plays a proapoptotic role in several models of neuronal cell death: inhibition of GSK3 $\beta$ promotes neuronal survival, whereas overexpression causes neuronal apoptosis ${ }^{44}$. Active/ dephosphorylated GSK3 $\beta$ induces PUMA expression by modulating FoxO3a activity, leading to neuronal cell death. We reported that inhibition of miR-711 partially restores the levels of total and phosphorylated/active Akt, as well as the levels of phosphorylated/inactive GSK3 $\beta$ after SCI. These alterations are correlated with reduced PUMA expression and cleavage fragments of $\alpha$-fodrin in the spinal cord after injury. Interventions preventing posttraumatic Akt inactivation can improve functional and histological outcomes after $\mathrm{SCI}^{21,40,45,46}$. miR-21 targets PTEN, an Akt inhibitor and the neuroprotective effects of 


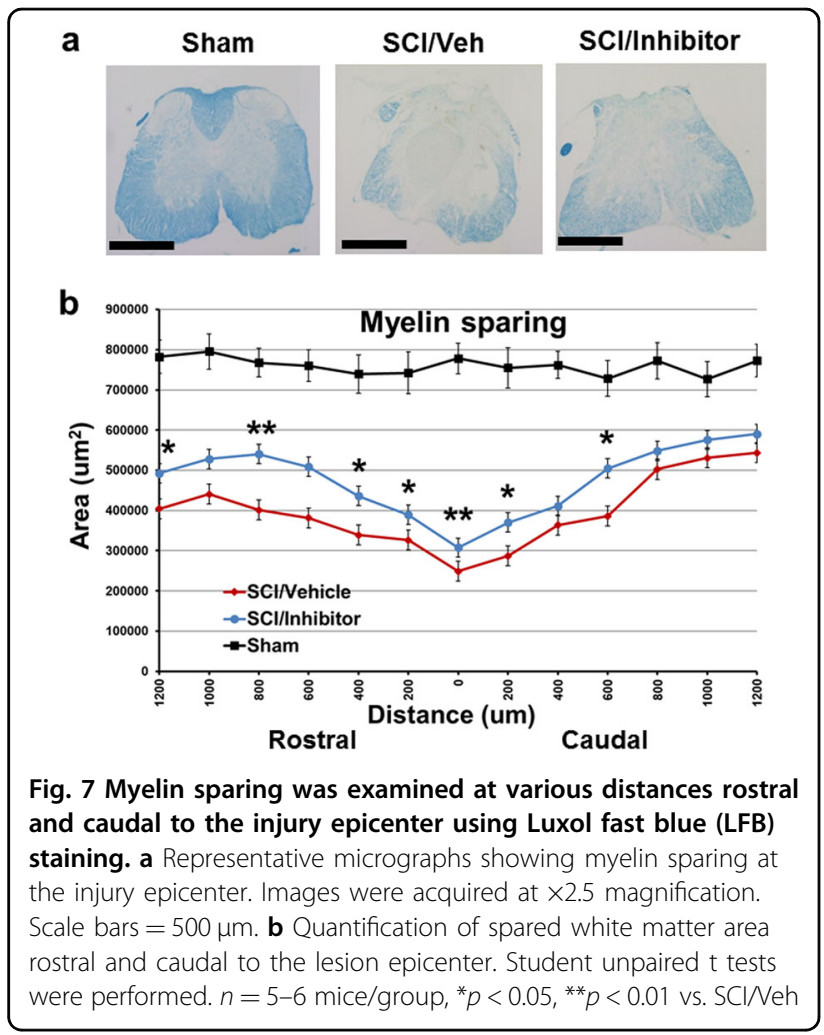

miR-21 mimics after TBI may reflect activation of the Akt pathway $^{36,47}$. In the present study, inhibition of miR-711 partially rescued the Akt/GSK3 $\beta$ signaling; this was associated with reduced neuronal cell death and axonal damage, as well as improved functional recovery.

Angiopoietin-1 (Ang-1) is recognized as an endothelial growth factor. Studies demonstrate that Ang-1 signal through the Tie2 receptor promotes endothelial cell survival, stabilizes blood vessels and reduces leakiness during developmental or tumor-associated angiogenesis ${ }^{48-50}$. Importantly, Ang-1 is another predicted target for miR711. We recently identified ${ }^{28}$ that miR-711 directly targets the Ang-1 messenger RNA, decreasing Ang-1 expression. We also observed short-term neuroprotective effects after Ang-1 administration after TBI. Previously, the neuroprotective effect of Vasculotide (Ang-1 Mimetic Peptide) was demonstrated in vivo in models of experimental stroke $^{29}$ : intraperitoneal injections with Vasculotide attenuated caspase activation and apoptosis. In SCI, an Ang-1 mimetic rescues epicenter blood vessels through its prosurvival role for endothelial cells, resulting in reduced inflammation, and improved white matter and locomotor function $^{51,52}$. Ang-1 is also expressed in CNS neurons and its neuroprotective role may involve, in part, Akt activation $^{29}$. In the present study, we showed that SCI induced a rapid downregulation of Ang-1 in the injured spinal cord that was sustained over several days. Inhibition of miR711 rescued epicenter blood vessels associated with
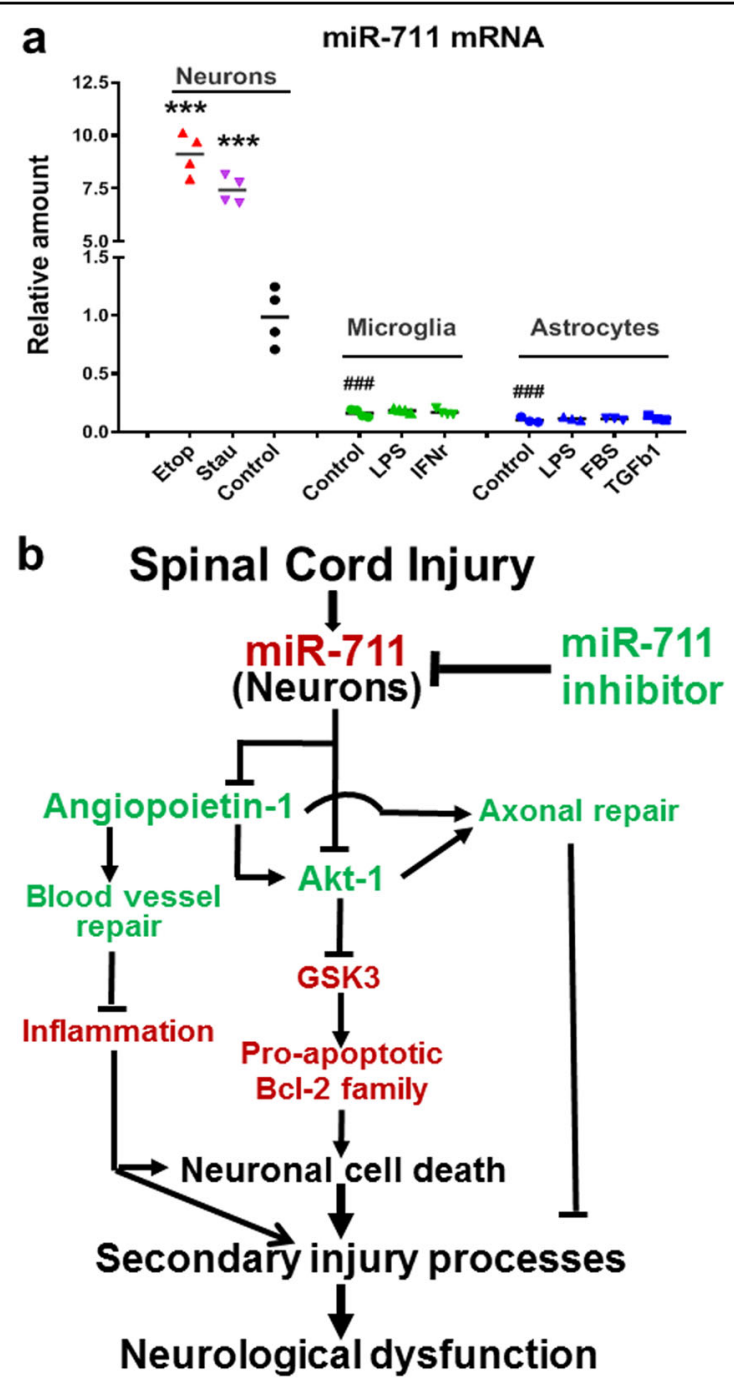

Fig. 8 a miR-711 is predominately expressed by neurons in vitro. miR-711 expression was analyzed by GPCR in primary cultured cortical neurons, microglia, and astrocytes. Neurons were exposed to cell death inducers etoposide (Etop, $25 \mathrm{nM}$ ) or staurosporine (Stau, $25 \mathrm{nM}$ ) for $6 \mathrm{~h}$, microglia were treated with LPS $(30 \mathrm{ng} / \mathrm{ml})$ or IFNy $(60 \mathrm{ng} / \mathrm{ml})$ for $24 \mathrm{~h}$, astrocytes were treated with LPS $(1 \mu \mathrm{g} / \mathrm{ml})$, TGF 1 1 $(30 \mathrm{ng} / \mathrm{ml})$, or $10 \% \mathrm{FBS}$ for $24 \mathrm{~h}$. The data are presented as independent data points. One-way ANOVA was conducted followed by Newman-Keuls multiple comparisons test. $n=3-5$ dishes/group repeated in three

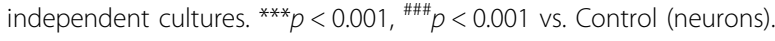
b The functional role of miR-711 in regulating neuronal cell death, axonal and blood vessel damage after SCl. SCl-induced elevation of miR-711 can initiate secondary injury pathways including neuronal cell death, axonal damage, and vascular disruption, through in part, inhibition of Akt and Angiopoietin-1 (Ang-1) pathways. Administration of miR-711 inhibitor in the acute period after SCl has significant neuroprotective effects, likely acting both directly on neurons and by limiting Ang-1-mediated vascular permeability effects

elevation of Ang-1. Thus, we speculate that promoting the endothelial-selective Ang-1 by miR-711 inhibitors may provide vascular protection and reduced inflammation, 
thereby improving functional outcomes. Whether or not miR-711 needs Ang-1 to function efficiently is intriguing for future investigation.

Increasing evidence suggests that miRNAs represent a new class of drug targets ${ }^{53-57}$, with several miRNAs evaluated both preclinically and clinically ${ }^{56-58}$. miRIDIAN microRNA Hairpin Inhibitors are the newest generation proprietary, synthetic inhibitors targeting all human, mouse, and rat microRNAs in the miRBase database release 21.0. miRIDIAN Hairpin Inhibitors are singlestranded, chemically enhanced RNA oligonucleotides designed to bind and to sequester the complimentary, mature microRNA strand. This design allows for microRNA inhibition to be maintained longer than with other available synthetic inhibitors. Importantly, enhanced potency and longevity allow for multiplexed microRNA inhibition at very low nanomolar concentrations and with minimal toxicity, which reduces the risk of negative and off-target side effects. We have successfully applied miRIDIAN microRNAs in a TBI model ${ }^{17,33}$ as well as in a SCI model here. The specificity of highly potent miRNA inhibitors has been tested (gelifesciences.com/dharmacon). They do not cross-react with non-family member miRNAs that share sequence similarity. As miR-711 does not have any family members, thus it is not a concern regarding the specificity of miR-711 inhibitor in suppressing miR-711 and whether the inhibitors may also have direct effects on the expression of other miRNAs.

Effects of miR-711 on cell proliferation have been controversial in cancer cell lines. In gastric cancer cell line, upregulated expression of miR-711 arrests the cells in the G1 phase by downregulating expression of cyclindependent kinases $4(\mathrm{CDK} 4)^{59}$, suggesting a participation of miR-711 signaling in cell cycle regulation. However, downregulating miR-711 inhibits cell proliferation, colony formation, migration and invasion and enhances the rate of apoptosis of breast cancer cells ${ }^{60}$. After SCI, a key pathophysiological mechanism appears to be cell cycle activation $(C C A)^{61}$. Experimental evidence in both SCI and TBI models, much from our laboratory, indicates that in post-mitotic cells such as neurons and mature oligodendroglia, CCA occurs post-trauma and contributes to neuronal cell death, whereas in microglia or astrocytes it causes proliferation and activation ${ }^{61}$. Although elevated miR-711 in gastric cancer cells showed suppression of $\mathrm{CDK} 4^{59}$, cell cycle machinery is a complicated process in vivo. Moreover, our data indicate that inhibition of miR-711 reduces neuronal cell death in vitro ${ }^{33}$ and in vivo after SCI, associated with reduced CCA. Whether or not elevated CCA in the injured spinal cord is suppressed by miR-711 inhibition remains to be determined.

miRNAs are implicated in the pathophysiology of CNS disorders but the underlying mechanisms have been difficult to study in part due to the cellular heterogeneity in vivo. miR-711 levels are rapidly elevated by neuronal insults in vitro ${ }^{33}$. We found significant lower level of miR711 in primary cultured astrocytes and microglia than that in cultured cortical neurons. LPS, $10 \%$ FBS, or TGF $\beta 1$ are known activate astrocytes but failed to stimulate miR-711 expression. Moreover, miR-711 levels in microglia remain unchanged in response to LPS or IFN $\gamma$, consistent with a previous report ${ }^{62}$. These data suggest that miR-711 is predominately expressed by neurons. However, miR-711 was reported to be downregulated in M2a-skewed microglia stimulation $(\mathrm{IL}-4)^{62}$, suggesting that reduced expression in miR-711 may regulate anti-inflammatory effects. Future studies should further examine cell specific miR-711 expression changes and its validated predicted targets (Akt and Ang-1) after CNS injuries.

Recent studies ${ }^{63,64}$ have shown that intravenous administration of microRNA inhibitors are effective in models of focal cerebral ischemia; the microRNA inhibitors reached the central nervous system and levels of the targeted microRNA in the brain were significantly reduced as early as $2 \mathrm{~h}$ after a single iv injection and remained low for at least $24 \mathrm{~h}^{63}$. Whether or not systemic treatment of miR-711 inhibitor is effective in spinal cord injury remains to be determined.

Gender-related differences after SCI have been reported with regard to neurologic changes and post-traumatic neuropathic pain ${ }^{65-68}$. Expression levels of miR-711 and Ang-1 in response to SCI were compared between male and female mice. No differences of miR-711 mRNA or Ang-1 mRNA were observed between the sexes (data not shown). However, whether miR-711 inhibitor-treatment effects differ between female and male mice should be examined in future studies.

In summary (Fig. $8 \mathrm{~b}$ ), we provide evidence that SCI induces an elevation of miR-711 expression and reduction of its targets Akt and Ang-1, which is correlated with neuronal cell death and axonal damage. Inhibition of miR711 by miRIDIAN microRNA Hairpin Inhibitors significantly rescues the Akt/GSK3 $\beta$ signaling as well as Ang-1 expression after SCI, associated with reduced neuronal/axonal damage and protection of epicenter blood vessels. Administration of miR-711 inhibitor in the acute period after SCI has significant neuroprotective effects, likely acting both directly on neurons and by limiting Ang-1-mediated vascular permeability effects. Treatment was associated with reduced tissue damage and marked improvement in functional recovery.

\section{Materials and methods}

Animals and contusive spinal cord injury

All experiments were conducted using adult male C57BL/6 mice (10-12 weeks, 20-25 g, purchased from Taconic, Rensselaer, NY). The animals were housed on a 12:12 h light/dark cycle with food and water freely 
available ad libitum. All procedures were carried out under protocols approved by the Institutional Animal Care and Use Committee (IACUC) at the University of Maryland School of Medicine. A moderate spinal cord contusion injury was induced using the Infinite Horizon (Precision Systems and Instrumentation) spinal cord impactor as previously described ${ }^{69-72}$. Briefly, mice were deeply anesthetized with isoflurane evaporated in a gas mixture containing 70\% $\mathrm{N}_{2} \mathrm{O}$ and $30 \% \mathrm{O}_{2}$ and administered through a nose mask (induction at $3 \%$ and maintenance at 1.5\%). The spinal column was stabilized using lateral clamps over the lateral processes at T9 and T11. A laminectomy was performed followed by a midline spinal contusions at T10 level with a force of $60 \mathrm{kdyn}$ for $2 \mathrm{~s}$ dwell time, a moderate injury. Control sham animals received laminectomy only. The bladders of injured mice were manually expressed 2-3 times per day until a reflex bladder emptying was established. After SCI, all mice were assigned to a treatment group according to a randomized block experimental design. Individuals performed functional assessment and involved in data analysis were blinded to group designations throughout all stages of the experiment. The number of mice at various time points in each study is indicated in the figure legends. All mice were assessed at various time points after injury by the same surgeon and at the same period of time.

\section{Intrathecal injection of miR-711 hairpin inhibitor}

miR-711 hairpin inhibitors (miRIDIAN microRNA mouse mmu-miR-711 hairpin inhibitor, IH-310774-030005) or negative controls (Vehicle, miRIDIAN microRNA hairpin inhibitor negative control; IN-001005-0105) were purchased from GE Healthcare Dharmacon Inc. and reconstituted in artificial cerebrospinal fluid (aCSF). Right after injury, the bilateral microinjections (2 injections/side, $1.25 \mu \mathrm{l} /$ injection, total $5 \mu \mathrm{l})$ of the miR-711 inhibitor or Vehicle (final concentration $0.5 \mathrm{nmol} /$ mouse) were made intrathecally at $1 \mathrm{~mm}$ from the midline $\mathrm{e}^{34}$. There was a $2 \mathrm{~mm}$ distance between the two injections on each side. The dose of the miR-711 inhibitor was based on the results obtained from in vitro cultured neurons and mouse TBI model ${ }^{33}$. Based on our pilot data showing no effects of miR-711 inhibitor in sham mice, Sham/Vehicle group served as controls. Animals were euthanized at $24 \mathrm{~h}$ following trauma for biochemical analysis.

As miR-711 expression levels show sustained elevation for several days, we also applied the additional treatment at $24 \mathrm{~h}$ post-injury for long-term behavioral tests, in which direct percutaneous intrathecal injections were made by lumbar puncture ${ }^{72}$. Briefly, mice were anesthetized with isoflurane and the pelvis was stabilized to allow the identification of the space between the L5 and L6 spinous processes. A $1 / 2$ inch $30 \mathrm{~g}$ needle attached to a $25 \mu \mathrm{l}$
Hamilton syringe was percutaneously inserted into the groove between the spinous and transverse processes of the L5 and L6 vertebrae at a $20^{\circ}$ angle in the rostral direction. Entry into the intrathecal space was determined by visualizing a quick tail flick during needle penetration, at which point the needle angle was decreased to $10^{\circ}$. miR-711 inhibitor ( $0.5 \mathrm{nmol}$ in $5 \mu \mathrm{l}$ aCSF per mouse) or the same amount of Vehicle were administered by intrathecal injection. The mice recovered under a warming lamp and were observed for signs of spinal trauma (hindlimb weakness, unsteady gait, dragging a hindpaw) beyond what is present due to the experimental SCI. Any mice with signs of spinal trauma were euthanized immediately.

\section{RNA isolation and quantitative polymerase chain reaction (qPCR) analysis}

Total RNA was isolated by using a miRNeasy isolation kit (QIAGEN) with on-column DNase treatment (QIAGEN). During the process of isolation, samples were treated with RNase-free DNase (Qiagen) to prevent DNA contamination of the samples according to the manufacturer's protocol. Verso cDNA Kit (Thermo Scientific) was used to synthesize cDNA from purified total RNA. RNA $(1 \mu \mathrm{g})$ was heated to $70^{\circ} \mathrm{C}$ for $5 \mathrm{~min}$ and mixed with $5 \mathrm{X}$ cDNA-synthesis buffer, dNTP mix $(0.5 \mathrm{nM}$ final concentration), Verso Enzyme Mix, and random hexamers $(400 \mathrm{ng} / \mu \mathrm{l})$ were added. Tubes were incubated at $42^{\circ} \mathrm{C}$ for $30 \mathrm{~min}$, followed by $95^{\circ} \mathrm{C}$ for $2 \mathrm{~min}$. Quantitative realtime PCR amplification was performed by using cDNA TaqMan Universal Master Mix II (Applied Biosystems). Briefly, reactions were performed in duplicate containing $10 \mu \mathrm{l}$ of $2 \mathrm{X}$ TaqMan Universal Master Mix II, $2 \mu \mathrm{l}$ of cDNA (corresponding to 50 ng RNA/reaction) and $1 \mu \mathrm{l}$ of $20 \mathrm{X}$ TaqMan Gene Expression assay primers in a final volume of $20 \mu \mathrm{l}$. TaqMan Gene Expression assays for following: GAPDH (Mm99999915_g1), Ang-1 (Mm00456503_m1) were used. Reactions were amplified and quantified using the QuantStudio 5 Real-Time PCR System and the corresponding software (Applied Biosystems). The PCR profile consisted of one cycle at $50^{\circ} \mathrm{C}$ for $2 \mathrm{~min}$ and $95^{\circ} \mathrm{C}$ for $10 \mathrm{~min}$, followed by 40 cycles of $95^{\circ} \mathrm{C}$ for $15 \mathrm{~s}$ and $60^{\circ} \mathrm{C}$ for $1 \mathrm{~min}$. The efficiency of reactions was measured using the CT slope method. Gene expression was normalized to GAPDH, and the relative quantity of mRNAs was calculated based on the comparative CT method $^{73}$. Analysis of relative gene expression data using real-time quantitative PCR and the 2(-Delta Delta $C(T)$ ) method.

\section{miR reverse transcription and miR-711 qPCR analysis}

qPCR was used to measure the expression of mature miR-711. Ten nanograms of total RNA was reverse transcribed using TaqMan miRNA Reverse Transcription 
Kit (Applied Biosystems) with miRNA-specific primers. Reverse transcription reaction products $(1.5 \mu \mathrm{l})$ were used for $\mathrm{qPCR}$ as described above. TaqMan Gene Expression assays for mmu-miR-711 (001646) and U6 snRNA (001973) (Applied Biosystems) were used. miR-711 expression was normalized to U6 snRNA.

\section{Western blots}

Mouse spinal cord tissue (approximately threemillimeter segments) centered on the injury site was harvested at indicated times after injury. Western blot analysis was performed as described previously ${ }^{72}$. Briefly, the tissues were homogenized in RIPA buffer (SigmaAldrich) supplemented $1 \mathrm{x}$ protease inhibitor cocktail (Sigma-Aldrich), phosphatase inhibitor cocktails II and III (Sigma-Aldrich), sonicated and centrifuged at 20,000 $\times g$ for $20 \mathrm{~min}$. Protein concentrations were determined by the Pierce BCA method (ThermoFisher Scientific, USA). Samples were run on 4-20\% SDS-PAGE (Bio-Rad, Hercules, CA), and transferred to nitrocellulose membrane (Bio-Rad). Primary antibodies included: mouse antiphospho Akt serine 473 (p-Akt; 1:500, Cat\# 4060, Cell signaling Technology, Inc., San Diego, CA), mouse antiphospho Akt threonine 308 (p-Akt; 1:500, Cat\# 9275, Cell signaling Technology), mouse anti-Akt (pan Akt, 11E7, 1:1000; Cat\# 4685, Cell signaling Technology, Inc.), rabbit anti-phospho-GSK3 $\alpha / \beta$ (Ser21/9, p-GSK3, 1:1000; Cat\# 9331, Cell signaling Technology, Inc.), rabbit anti-GSK3 $\alpha /$ $\beta$ (D75D3, GSK3 $\alpha / \beta, 1: 1000$; Cat\# 5676, Cell signaling Technology, Inc.), rabbit anti-PUMA (1:1000; Cat\# 3041, ProSci Incorporated), mouse anti- $\alpha$-fodrin (1:5000; Cat\# BML-FG6090, Enzo Life Sciences), Angiopoietin-1 (1:1000; Cat\# GTX28451, GeneTex Inc.), and mouse anti- $\beta$-actin (1:5000; Cat\# AB2302, Millipore, Temecula, $\mathrm{CA})$. Immune complexes were detected with the appropriate HRP conjugated secondary antibodies (KPL, Inc., Gaithersburg, MD) and visualized using SuperSignal West Dura Extended Duration Substrate (Thermo Scientific, Rockford, IL). Chemiluminescence was captured on a Kodak Image Station $4000 \mathrm{R}$ station (Carestream Health Inc., Rochester, NY) and protein bands were quantified by densitometric analysis using Carestream Molecular Imaging Software (Carestream Health Inc., Rochester, NY). The data presented reflects the intensity of target protein band compared with control and normalized based on the intensity of the endogenous control for each sample (expressed in fold of sham).

\section{Behavioral assessments Locomotor testing (BMS score)}

All behavioral tests were blindly performed. Mice were tested for hindlimb function in open-field locomotion on day 1 after injury and weekly thereafter for up to 6 weeks using the Basso mouse scale (BMS) for locomotion $^{74}$. Briefly, mice were placed in an open-field chamber (diameter $=40 \mathrm{in}$ ) and observed for $4 \mathrm{~min}$ by two trained observers. Animals were rated on a scale of 0-9: 0 being complete paralysis, and 9 being normal locomotion based on hind limb joint movement, weight support, plantar stepping, and coordination. A minimum score of 4, or occasional plantar stepping, was required to evaluate each animal in additional measures for pain-like behaviors as well as more sensitive measures of motor and coordinative recovery.

\section{CatwalkXT auto mated gait analysis}

Gait analysis was performed using the CatwalkXT automated system ${ }^{69}$ (Noldus; RRID:SCR_004074). Each mouse underwent only one testing session at 5 weeks after SCI to maintain situational novelty and encourage exploration of the CatWalk. Data acquisition took place in a darkened room with the same researcher handling each subject. The CatWalk itself features a red overhead lamp and green illuminated walkway, which responds to the pressure of the animals' weights and obtains live foot print videos. Animals were first placed in the open end of the CatWalk under the red ceiling light and allowed to walk across the walkway to the darkened escape enclosure. A minimum of three valid runs, or complete walkway crossings, were obtained for each subject. Trials in which the animal stopped partway across or turned around during a run were excluded from analysis. The primary variables were print position (the distance between the hind and forepaw of one side during gait) for motor coordination, and regularity index (the percentage of step cycles that can be characterized as fitting a standard pattern of gait).

\section{Tissue processing and assessment of white matter sparing}

Following animal perfusion with $4 \%$ paraformaldehyde, spinal cord segments containing the lesion area were dissected out, embedded, and cut into $20-\mu \mathrm{m}$-thick serial sections placed serially on set of 10 slides for 10 sets of slides. A representative slide from each set was then stained for myelin using Luxol fast blue (LFB) to determine the location of the lesion epicenter, defined as the section with the least amount of spared white matter (WM). Residual WM was also calculated for areas rostral and caudal to the lesion epicenter ${ }^{72}$. Images were captured at $\times 2.5$ magnification and analyzed using National Institutes of Health ImageJ software (RRID:SCR_003070). The threshold level of each 8 bit image was set to mark only LFB-positive tissue, and total LFB-positive area was calculated for each section. 
Immunohistochemistry, image acquisition, and quantification

Immunofluorescence staining was followed procedures described previously ${ }^{69,72}$. Briefly, slides were first washed gently in PBS, dried, and placed in a vacuum chamber for 20 min to promote adhesion. Tissue was then blocked in $5 \%$ normal goat serum for $1 \mathrm{~h}$, and incubated overnight at $4{ }^{\circ} \mathrm{C}$ in primary antibodies, including PhosphoDetect ${ }^{\mathrm{TM}}$ Anti-Neurofilament-H Mouse mAb (SMI-31, 1:1000; Sigma-Aldrich, NE1022), NeuN (1:500; Millipore, MAB377), and von Willebrand factor (vWF, 1:1000; Millipore, AB7356). The next day, slides were washed and incubated for $2 \mathrm{~h}$ in fluorescent secondaries (Alexa fluor), and washed again. Then DAPI nuclear stain (SigmaAldrich) was added for $30 \mathrm{~min}$ before a final wash, followed by cover slipping in non-fluorescing mounting medium (National Diagnostics, HS-106). All immunohistological staining experiments were performed with appropriate positive control tissue as well as primary/ secondary-only negative controls.

For quantitative image analysis, images were acquired using a fluorescent Nikon Ti-E inverted microscope, at 20× (CFI Plan APO VC 20×; numerical aperture, 0.75; working distance, $1 \mathrm{~mm}$ ) magnification and quantified using NIS-Elements AR software (Nikon). Exposure times were kept constant for all sections in each experiment. Background for all images was subtracted using Elements. All images were quantified using Elements: nuclei were identified using Spot Detection algorithm based on DAPI staining; cells positive for any of the immunofluorescence markers were identified using Detect Regional Maxima or Detect Peak salgorithms, followed by global thresholding. The number or immunointensity of positive cells was normalized to the total area imaged. The immunointensity of SMI-31 positive signals were acquired from both sides of dorsal, ventral, and lateral whiter matter. The number of NeuN labeled cells were acquired at rostral or caudal to the epicenter with total \# from both sides of ventral horns $(\mathrm{VH})$, dorsal horns $(\mathrm{DH})$, and intermediate gray matter. To assess effects of damaged neurons on the blood vessels, the immunointensity of vascular density were acquired from the grey matter. All images were acquired $2-3 \mathrm{~mm}$ rostral or caudal to the epicenter, with $n=15-20$ images per location from 10 to 15 sections per mouse. All images were captured from $n=7-9$ mice per group. For each experiment, data from all images from one region in each mouse were summed up and used for final statistical analysis. At least 1000-2000 cells were quantified per mouse per area per experiment ${ }^{75,76}$. The images were processed using Adobe Photoshop7.0 software (Adobe Systems).

\section{Primary neurons, microglia, and astrocytes culture}

Primary neuronal cultures were derived from E18 rat cerebral cortices, as previously described ${ }^{77}$. Cells were seeded onto poly-D-lysine-coated $(50 \mu \mathrm{g} / \mathrm{ml}, 70-150 \mathrm{kDa}$, Sigma-Aldrich, Cat\# P6407) $10 \mathrm{~cm}$ Petri dishes (cell density $1 \times 10^{6} / \mathrm{cm}^{2}$ ) and maintained in serum-free conditions using Neurobasal medium supplemented with $2 \%$ B27, $25 \mathrm{mM}$ Naglutamate, and $0.5 \mathrm{mM}$ L-glutamine. At 7 days after the culture, neurons were exposed to cell death inducers etoposide (Etop, $25 \mathrm{nM}$ ) or staurosporine (Stau, $25 \mathrm{nM}$ ) for $6 \mathrm{~h}$,

Primary mixed glia were cultured from the cerebral cortex of neonatal rats as described ${ }^{77}$. The cells were plated in T75 flasks and grown in Dulbecco's modified Eagle's medium (DMEM)/F12 supplemented with 10\% FBS, 1\% Pen/Strep at $37^{\circ} \mathrm{C}$ with $5 \% \mathrm{CO}_{2}$. When the cells had grown to confluence, the flasks were shaken at $100 \mathrm{rpm}$ for $1 \mathrm{~h}$ at $37^{\circ} \mathrm{C}$ and the supernatant contained enriched microglia. The flasks were continuously shaken for 2-3 days, the remaining cells were enriched astrocytes. The yield microglia and astrocytes were re-plated in 3.5 or $6 \mathrm{~cm}$ dishes. When microglia had reached confluence, LPS $(30 \mathrm{ng} / \mathrm{ml})$ or IFN $\gamma$ $(60 \mathrm{ng} / \mathrm{ml})$ were applied to the dish for $24 \mathrm{~h}$. The astrocytes were treated with LPS $(1 \mu \mathrm{g} / \mathrm{ml})$, TGF $\beta 1(30 \mathrm{ng} / \mathrm{ml})$, or $10 \%$ FBS for $24 \mathrm{~h}$. The cell lysates were harvested for RNA extraction and miR-711 qPCR analysis.

\section{Statistical analysis}

Quantitative data were plotted as mean \pm standard error of the mean or independent data points. The number of animals in all studies was determined by power analysis (power of 0.8 with alpha value 0.05 ). For the BMS scores, repeated measures two-way analyses of variance (ANOVAs) were conducted, followed by Newman-Keuls multiple comparisons test to compare the differences between groups. Statistical significance was evaluated between two individual samples using Student unpaired $t$ tests. For multiple comparisons, one-way analysis of variance (ANOVA) followed by Newman-Keuls multiple comparisons test. Statistical analysis was performed using SigmaPlot Program, Version 12 (Systat Software) or GraphPad Prism software, version 4.00 for windows (GraphPad Software, Inc). A $p$ value of $<0.05$ was considered statistically significant.

\section{Acknowledgements \\ The authors disclosed receipt of the following financial support for the research, authorship, and/or publication of this article: The work was supported by the National Institutes of Health Grants R01 NS094527 (J.W.), 2 R01 NR013601 (J.W./A.I.F.), R01 NS1 10635 (J.W./A.I.F.), R01 NS110567 (J.W.), RF1 NS1 10637 (J.W.), R01 NS096002 (B.A.S.B.S.), and Craig H. Nielson Foundation Research (340442) (A.I.F.).}

Conflict of interest

The authors declare that they have no conflict of interest.

\section{Publisher's note}

Springer Nature remains neutral with regard to jurisdictional claims in published maps and institutional affiliations. 
Supplementary Information accompanies this paper at (https://doi.org/ 10.1038/s41419-019-2079-y).

Received: 15 September 2019 Revised: 9 October 2019 Accepted: 18 October 2019

Published online: 04 November 2019

\section{References}

1. Griffiths-Jones, S. Annotating noncoding RNA genes. Annu. Rev. genomics Hum. Genet. 8, 279-298 (2007).

2. Krol, J. et al. Characterizing light-regulated retinal microRNAs reveals rapid turnover as a common property of neuronal microRNAs. Cell 141, 618-631 (2010).

3. Schratt, G. microRNAs at the synapse. Nat. Rev. Neurosci. 10, 842-849 (2009).

4. Henshall, D. C. MicroRNA and epilepsy: profiling, functions and potential clinical applications. Curr. Opin. Neurol. 27, 199-205 (2014).

5. Ponomarev, E. D., Veremeyko, T. \& Weiner, H. L. MicroRNAs are universal regulators of differentiation, activation, and polarization of microglia and macrophages in normal and diseased CNS. Glia 61, 91-103 (2013).

6. Lei, P., Li, Y., Chen, X., Yang, S. \& Zhang, J. Microarray based analysis of microRNA expression in rat cerebral cortex after traumatic brain injury. Brain Res 1284, 191-201 (2009).

7. Liu, D. Z. et al. Brain and blood microRNA expression profiling of ischemic stroke, intracerebral hemorrhage, and kainate seizures. J. Cereb. Blood Flow. Metab. 30, 92-101 (2010).

8. Redell, J. B., Liu, Y. \& Dash, P. K. Traumatic brain injury alters expression of hippocampal microRNAs: potential regulators of multiple pathophysiological processes. J. Neurosci. Res. 87, 1435-1448 (2009).

9. Ziu, M., Fletcher, L., Rana, S., Jimenez, D. F. \& Digicaylioglu, M. Temporal differences in microRNA expression patterns in astrocytes and neurons after ischemic injury. PLOS ONE 6, e14724 (2011).

10. Liu, N. K., Wang, X. F., Lu, Q. B. \& Xu, X. M. Altered microRNA expression following traumatic spinal cord injury. Exp. Neurol. 219, 424-429 (2009).

11. Nieto-Diaz, M. et al. MicroRNA dysregulation in spinal cord injury: causes, consequences and therapeutics. Front. Cell. Neurosci. 8, 53 (2014).

12. $\mathrm{Hu}, \mathrm{J}$. Z. et al. Anti-apoptotic effect of microRNA-21 after contusion spinal cord injury in rats. J. Neurotrauma 30, 1349-1360 (2013).

13. Jee, M. K., Jung, J. S., Im, Y. B., Jung, S. J. \& Kang, S. K. Silencing of miR20a is crucial for Ngn1-mediated neuroprotection in injured spinal cord. Hum. Gene Ther. 23, 508-520 (2012)

14. Jee, M. K. et al. MicroRNA 486 is a potentially novel target for the treatment of spinal cord injury. Brain 135, 1237-1252 (2012).

15. Kole, A. J. Swahari, V., Hammond, S. M. \& Deshmukh, M. miR-29b is activated during neuronal maturation and targets $\mathrm{BH}$-only genes to restrict apoptosis. Genes Dev. 25, 125-130 (2011).

16. Ouyang, Y. B., Lu, Y., Yue, S. \& Giffard, R. G. miR-181 targets multiple Bcl-2 family members and influences apoptosis and mitochondrial function in astrocytes. Mitochondrion 12, 213-219 (2012).

17. Sabirzhanov, B. et al. Downregulation of miR-23a and miR-27a following experimental traumatic brain injury induces neuronal cell death through activation of proapoptotic Bcl-2 proteins. J. Neurosci. 34, 10055-10071 (2014).

18. Mohite, A., Chillar, A., So, S. P., Cervantes, V. \& Ruan, K. H. Novel mechanism of the vascular protector prostacyclin: regulating microRNA expression. Biochemistry 50, 1691-1699 (2011).

19. Tranter, M. et al. Coordinated post-transcriptional regulation of Hsp70.3 gene expression by microRNA and alternative polyadenylation. J. Biol. Chem. 286, 29828-29837 (2011)

20. Zhou, L. et al. MicroRNA and mRNA signatures in ischemia reperfusion injury in heart transplantation. PLOS ONE 8, e79805 (2013).

21. Ohtake, Y. et al. The effect of systemic PTEN antagonist peptides on axon growth and functional recovery after spinal cord injury. Biomaterials $\mathbf{3 5}$ 4610-4626 (2014).

22. Walker, C. L, Liu, N. K. \& Xu, X. M. PTEN/PI3K and MAPK signaling in protection and pathology following CNS injuries. Front. Biol. 8, https://doi.org/10.1007/ s11515-013-1255-1 (2013).

23. He, Z. Intrinsic control of axon regeneration. J. Biomed. Res. 24, 2-5 (2010).

24. Nawabi, H., Zukor, K. \& He, Z. No simpler than mammals: axon and dendrite regeneration in Drosophila. Genes Dev. 26, 1509-1514 (2012).
25. Dill, J., Wang, H., Zhou, F. \& Li, S. Inactivation of glycogen synthase kinase 3 promotes axonal growth and recovery in the CNS. J. Neurosci. 28, 8914-8928 (2008).

26. Fiedler, U. \& Augustin, H. G. Angiopoietins: a link between angiogenesis and inflammation. Trends Immunol. 27, 552-558 (2006).

27. Thurston, $G$. et al. Leakage-resistant blood vessels in mice transgenically overexpressing angiopoietin-1. Science 286, 2511-2514 (1999).

28. Sabirzhanov, B. et al. MicroRNA-711-Induced Downregulation of Angiopoietin1 Mediates Neuronal Cell Death. J. Neurotrauma 35, 2462-2481 (2018).

29. Valable, S. et al. Angiopoietin-1-induced PI3-kinase activation prevents neuronal apoptosis. FASEB J. 17, 443-445 (2003).

30. Kosacka, J. et al. Angiopoietin-1 promotes neurite outgrowth from dorsal root ganglion cells positive for Tie-2 receptor. Cell Tissue Res. 320, 11-19 (2005).

31. Chen, J. et al. Niaspan increases angiogenesis and improves functional recovery after stroke. Ann. Neurol. 62, 49-58 (2007).

32. Yan, T. et al. Niaspan increases axonal remodeling after stroke in type 1 diabetes rats. Neurobiol. Dis. 46, 157-164 (2012)

33. Sabirzhanov, B. et al. miR-711 upregulation induces neuronal cell death after traumatic brain injury. Cell Death Differ. https://doi.org/10.1038/cdd.2015.132 (2015).

34. Wu, J. et al. Ablation of the transcription factors E2F1-2 limits neuroinflammation and associated neurological deficits after contusive spinal cord injury. Cell Cycle 14, 3698-3712 (2015)

35. Lu, D., Mahmood, A., Zhang, R. \& Copp, M. Upregulation of neurogenesis and reduction in functional deficits following administration of DEtA/NONOate, a nitric oxide donor, after traumatic brain injury in rats. J. Neurosurg. 99, 351-361 (2003).

36. Ge, X. T. et al. miR-21 improves the neurological outcome after traumatic brain injury in rats. Sci. Rep. 4, 6718 (2014).

37. Hamers, F. P., Lankhorst, A. J., van Laar, T. J., Veldhuis, W. B. \& Gispen, W. H. Automated quantitative gait analysis during overground locomotion in the rat: its application to spinal cord contusion and transection injuries. J. Neurotrauma 18, 187-201 (2001).

38. Farook, J. M. et al. GADD34 induces cell death through inactivation of Akt following traumatic brain injury. Cell death Dis. 4, e754 (2013).

39. Noshita, N., Lewen, A., Sugawara, T. \& Chan, P. H. Akt phosphorylation and neuronal survival after traumatic brain injury in mice. Neurobiol. Dis. 9, 294-304 (2002).

40. Walker, C. L. et al. Systemic bisperoxovanadium activates Akt/mTOR, reduces autophagy, and enhances recovery following cervical spinal cord injury. PLoS ONE 7, e30012 (2012)

41. Hu, J., Zeng, L., Huang, J., Wang, G. \& Lu, H. miR-126 promotes angiogenesis and attenuates inflammation after contusion spinal cord injury in rats. Brain Res. 1608, 191-202 (2015).

42. Yu, F., Sugawara, T., Maier, C. M., Hsieh, L. B. \& Chan, P. H. Akt/Bad signaling and motor neuron survival after spinal cord injury. Neurobiol. Dis. 20, 491-499 (2005).

43. $\mathrm{Hu}, \mathrm{L}$. Y. et al. ATP-mediated protein kinase B Akt/mammalian target of rapamycin mTOR/p70 ribosomal S6 protein p70S6 kinase signaling pathway activation promotes improvement of locomotor function after spinal cord injury in rats. Neuroscience 169,1046-1062 (2010).

44. Ambacher, K. K. et al. The JNK- and AKT/GSK3beta-signaling pathways converge to regulate Puma induction and neuronal apoptosis induced by trophic factor deprivation. PLOS ONE 7, e46885 (2012)

45. Wang, C., Wang, P., Zeng, W. \& Li, W. Tetramethylpyrazine improves the recovery of spinal cord injury via Akt/Nrf2/HO-1 pathway. Bioorg. Med Chem. Lett. 26, 1287-1291 (2016).

46. Wu, C.-H. et al. Post-injury treatment with 7,8-dihydroxyflavone, a TrkB receptor agonist, protects against experimental traumatic brain injury via PI3KAK signaling. PLOS ONE 9, e113397 (2014).

47. Han, Z. et al. miR-21 alleviated apoptosis of cortical neurons through promoting PTEN-Akt signaling pathway in vitro after experimental traumatic brain injury. Brain Res. 1582, 12-20 (2014).

48. Mochizuki, N. Vascular integrity mediated by vascular endothelial cadherin and regulated by sphingosine 1-phosphate and angiopoietin-1. Circulation J. 73 2183-2191 (2009).

49. Nambu, $H$. et al. Angiopoietin 1 inhibits ocular neovascularization and breakdown of the blood-retinal barrier. Gene Ther. 11, 865-873 (2004).

50. Carmeliet, P. Angiogenesis in health and disease. Nat. Med. 9, 653-660 (2003). 
51. Han, S. et al. Rescuing vasculature with intravenous angiopoietin-1 and alpha v beta 3 integrin peptide is protective after spinal cord injury. Brain 133 1026-1042 (2010)

52. Herrera, J. J., Sundberg, L. M., Zentilin, L., Giacca, M. \& Narayana, P. A. Sustained expression of vascular endothelial growth factor and angiopoietin-1 improves blood-spinal cord barrier integrity and functional recovery after spinal cord injury. J. Neurotrauma 27, 2067-2076 (2010).

53. Esau, C. C. \& Monia, B. P. Therapeutic potential for microRNAs. Adv. Drug Deliv. Rev. 59, 101-114 (2007).

54. Mirnezami, A. H., Pickard, K., Zhang, L., Primrose, J. N. \& Packham, G. MicroRNAs: key players in carcinogenesis and novel therapeutic targets. Eur. J. Surgical Oncol. 35, 339-347 (2009).

55. Weiler, J., Hunziker, J. \& Hall, J. Anti-miRNA oligonucleotides (AMOs): ammunition to target miRNAs implicated in human disease? Gene Ther. 13, 496-502 (2006).

56. Christopher, A. F. et al. MicroRNA therapeutics: discovering novel targets and developing specific therapy. Perspect. Clin. Res. 7, 68-74 (2016).

57. Li, Z. \& Rana, T. M. Therapeutic targeting of microRNAs: current status and future challenges. Nat. Rev. Drug Discov. 13, 622-638 (2014).

58. Broderick, J. A. \& Zamore, P. D. MicroRNA therapeutics. Gene Ther. 18 1104-1110 (2011).

59. Liao, A., Tan, G., Chen, L., Zhou, W. \& Hu, H. RASSF1A inhibits gastric cancer cell proliferation by miR-711- mediated downregulation of CDK4 expression. Oncotarget 7, 5842-5851 (2016).

60. Hu, J. Y. et al. MicroRNA-711 is a prognostic factor for poor overall survival and has an oncogenic role in breast cancer. Oncol. Lett. 11, 2155-2163 (2016).

61. Wu, J. F., Stoica, B. A. \& Faden, A. I. Cell cycle activation and spinal cord injury. Neurotherapeutics 8, 221-228 (2011)

62. Freilich, R. W., Woodbury, M. E. \& Ikezu, T. Integrated expression profiles of mRNA and miRNA in polarized primary murine microglia. PLOS ONE 8, e79416 (2013).

63. Xu, L. J., Ouyang, Y. B., Xiong, X., Stary, C. M. \& Giffard, R. G. Post-stroke treatment with miR-181 antagomir reduces injury and improves long-term behavioral recovery in mice after focal cerebral ischemia. Exp. Neurol. 264, 1-7 (2015).

64. Caballero-Garrido, E. et al. In vivo inhibition of miR-155 promotes recovery after experimental mouse stroke. J. Neurosci. 35, 12446-12464 (2015).
65. Datto, J. P. et al. Female rats demonstrate improved locomotor recovery and greater preservation of white and gray matter after traumatic spinal cord injury compared to males. J. Neurotrauma 32, 1146-1157 (2015).

66. Chan, W. M., Mohammed, Y., Lee, I. \& Pearse, D. D. Effect of gender on recovery after spinal cord injury. Transl. Stroke Res. 4, 447-461 (2013).

67. Sipski, M. L., Jackson, A. B., Gomez-Marin, O., Estores, I. \& Stein, A. Effects of gender on neurologic and functional recovery after spinal cord injury. Arch. Phys. Med. Rehabilitation 85, 1826-1836 (2004).

68. Farooque, M. et al. Gender-related differences in recovery of locomotor function after spinal cord injury in mice. Spinal cord. 44, 182-187 (2006).

69. Matyas, J. J. et al. Truncated TrkB.T1-mediated astrocyte dysfunction contributes to impaired motor function and neuropathic pain after spinal cord injury. J. Neurosci. 37, 3956-3971 (2017).

70. Wu, J. et al. Endoplasmic reticulum stress and disrupted neurogenesis in the brain are associated with cognitive impairment and depressive-like behavior after spinal cord injury. J. Neurotrauma, https://doi.org/10.1089/neu.2015.4348 (2016).

71. $\mathrm{Wu}$, J. et al. Spinal cord injury causes brain inflammation associated with cognitive and affective changes: role of cell cycle pathways. J. Neurosci. 34, 10989-11006 (2014).

72. Wu, J., Renn, C. L., Faden, A. I. \& Dorsey, S. G. TrkB.T1 contributes to neuropathic pain after spinal cord injury through regulation of cell cycle pathways. J. Neurosci. 33, 12447-12463 (2013).

73. Livak, K. J. \& Schmittgen, T. D. Analysis of relative gene expression data using real-time quantitative PCR and the 2(-Delta Delta $C(T)$ ) method. Methods $\mathbf{2 5}$ 402-408 (2001).

74. Basso, D. M., Beattie, M. S. \& Bresnahan, J. C. A sensitive and reliable locomotor rating scale for open field testing in rats. J. Neurotrauma 12, 1-21 (1995).

75. Liu, S. et al. Disrupted autophagy after spinal cord injury is associated with ER stress and neuronal cell death. Cell Death Dis. 6, e1582 (2015).

76. Liu, S. et al. Lysosomal damage after spinal cord injury causes accumulation of RIPK1 and RIPK3 proteins and potentiation of necroptosis. Cell Death Dis. 9 476 (2018).

77. Wu, J., Raver, C., Piao, C., Keller, A. \& Faden, A. I. Cell cycle activation contributes to increased neuronal activity in the posterior thalamic nucleus and associated chronic hyperesthesia after rat spinal cord contusion. Neurotherapeutics 10, 520-538 (2013). 